\title{
The Course Teaching Reform Research of Communication Principle in Electronic Information Engineering Professional
}

\author{
Faquan Yang, Lijun Feng \\ School of Electronic and Information Engineering, Foshan University, Foshan, 528000, China \\ email: Yafaquan.fosu@163.com, email: Lijun@163.com
}

\begin{abstract}
Keywords: Communication principle; Teaching idea, teaching method, teaching content, experiment teaching
\end{abstract}

\begin{abstract}
Communication principle is a compulsory foundation course of electronic information engineering major, and it plays an important role in teaching undergraduate major of the electronic information engineering. However, with the increasing reform of talent training plan, the teaching time of professional course constantly suffer from the compression. Meanwhile, wide range of the teaching content and fewer teaching hours become the problems increasingly. Therefore, how to organize an effective classroom teaching under the limited teaching time has become one of hot topics which are discussed by the teachers from the related major. Based on the recent research and exploration, the problem can be solved well in this article through the teaching idea, teaching method, teaching content and experimental teaching. This article is through the reforms in the teaching idea, teaching method, teaching content and experimental teaching.
\end{abstract}

\section{Introduction}

The main content of the communication principle course includes the composition of communication system, classification, performance index, channel, analog modulation, transmission of digital signal baseband, carrier transmission, channel multiplexing, and new modulation technology of digital bandpass, error control coding, synchronization, communication network and other basic principle, Pulse coding, delta modulation, differential encoding and self-adaptive differential encoding modulation and other basic theory of the analog signal digital transmission.

Quadrature modulation, orthogonal frequency division multiplexing, spread spectrum technology, multiple access communications (FDMA, TDMA, CDMA), and other the basic theories of modern modulation technology and communication system [1]. Communication principle course content is wide, abstract, complex and systemic so students generally reflect the course is difficult to learn while the teachers also feel not easy to teach. With the rapid development of electronic information industry and communication technology is enhanced increasingly, continuing the traditional teaching methods to carry out the communication principle course teaching cannot meet the needs of students in adapting the electronic information industry. In order to make students easier to learn the courses, apply the communication principle and improving the student the practical ability, application ability, innovation ability, course teaching reform is imperative. Especially on the basis of the new talents cultivation plan, how to improve the teaching quality of communication principle is the main topics explored by the related teachers from each university. Therefore, this paper argues that the key to solve problem is to renew the teaching idea, improve the teaching method, choose the right teaching content, and reform the experiment teaching etc. In order to improve the teaching quality of communication principle for adapting to the development of modern communication technology and the teaching demand of the undergraduate colleges, I constantly study and explore the teaching method of communication principle for the actual situation of our university in the last few years. Now, I preliminary formed the course teaching system which has the characteristics of our university and obtained the good teaching effect. 


\section{Update of Teaching Concept, Teaching Method}

Due to the limited class hour, we have no method to do perfectly when teaching so we should updated the traditional teaching concept and teaching methods. In the teaching plan of undergraduate course, professional curriculum is mostly divided into technology basic course, professional basic course and specialized course. Regarding to the teaching schedule, technology basic course should be firstly learned, then technology basic course is followed by professional basic course and final course is specialized course. Certainly, there are consistency and permeability among different courses in the teaching content. If different comprehensive courses can be integrated studied, continuity can be reached in the teaching process, and the overlap can be minimized to the greatest extent, the teaching content will be arranged by tight and reasonable schedule, the teaching content will tend to be more coherent and systematic, the study hours will be effectively saved, and the teaching efficiency will be improved. Communication principle is as the specialized fundamental course of the information discipline and it has close connection with the signal and system and random signal analysis which are the prerequisite courses. Communication principle course has a lot of knowledge based on the concept of signal or system, Theory knowledge of random signal becomes the important theoretical basis and effective methods of the modern signal processing and it plays the vital role in the knowledge structure of the communication and information system, signal and information processing, electronic information science technology and other professional. The communication principle and the random signal are the important foundation course in the information engineering discipline and they requires the students have high foundation of mathematics. Generally, most of the teachers will only focus on the theoretical analysis of the mathematics level and it causes the isolation between theory and practice so that students feel the course content is multifarious, is difficult to be understood and the students do not know how to handle. In other words, students don't know what these technical basic courses can be used for and where they can be used for before they did not touch upon the professional basic course. Therefore, in the beginning of teaching these two courses, the teachers should let the students know the essence of communication is an effective and reliable transmission and exchange of information, and the signal is a means of transmitting information so the students should has a comprehensive analysis and understanding of known signal and random signal before studying the professional basic course. The theoretical foundation of the signal is the mathematical tool of a lot of the follow-up professional courses, such as communication principle. The follow-up communication principle courses discuss how to extract useful signal and intend to introduce the modulation technology from the perspective that signals can be transferred through the practical communication systems. When studying such technical basic course, the professional teacher from the perspective of profession can discuss the functions of the teaching course in the subsequent course of communication principle and its practical application so as to get twice the result with half the effort. Hence, I think the teachers require the students master the basic concept, the theories and methods of signal and random signal analysis and processing. In addition, the teachers should make the students know how to analyze and describe the time domain and frequency domain of the signal, and understand a whole set of theories when analyzing the system (linear and nonlinear) is the basis of analyzing all communication system when teaching signal and random signal analysis. In actual communication system as the main application background, combining frequency spectrum analysis and signal bandwidth, the system analysis and channel transmission characteristics and channel bandwidth, lets the student understand the signal and system analysis in order to better analysis and design is the purpose of the communication system. Such a target, in the subsequent communication principle related content on autopilot, natural transition [2]. In our school chooses fan owing by the communication principle (version 6) as an example, in the practice of teaching, learning chapter 2 known signal and stochastic process, chapter 3, due to the first signal and system of basic courses in professional technology and random signal analysis when studying the two courses "what's the use of, where is the" problem has been solved in advance, students have better, just grasp to review, put forward the key learning points and requirements, can save at least four hours of teaching time. 
(MATLAB/Simulink) and communication principle of some theoretical knowledge in the course are abstract, not understanding, but through the proper application of simulation software (MATLAB/Simulink) communication [3]. Using computer simulation analysis instead of boring tedious theoretical analysis and deduction, including classroom teachers under the simulation teaching and the course of students of simulation practice two aspects. Through simulation teaching classroom, teachers, build communication principle course need all kinds of communication system in the teaching process, and the working process of the analysis system and the effectiveness of the system, reliability, and through this process, many abstract abstruse theory into image, vivid and concrete, the students can better understand the formula to express meaning, from graphics to further deepen the understanding of knowledge and master. From rote remember formulas into give priority to in order to understand the formula and graphics, reduce the students' difficulties in the learning process, so as to effectively improve students' learning enthusiasm and interest, train the ability of independent innovation, improve the ability of problem solving and comprehensive design ability. In teaching of 2 PSK modulation demodulation principle, for example, in the coherent demodulation get and receive 2 PSK signal of the same frequency and phase coherent carrier is crucial, but exists in the demodulation local carrier recovery $180^{\circ}$ phase ambiguity, which would lead to "the phenomenon of the PI" [4]. Common to this "the phenomenon of the PI" more confused. For this, I according to the principle of building a simple based on (MATLAB/Simulink) simulation model of 2 PSK modulation demodulation system simulation model is the key point of the system Settings window, real-time observation signal waveform and system running situation, so that the system signal process and transformation have an intuitive understanding, dynamic, and convenient observation simulation model of the source code (absolute), coherent, 2 PSK modulated carrier wave signal, demodulation output multiplier, sampling output decision is absolute code (recovery).

\section{The Choice of Teaching Content}

Due to the limited class hour and I were talking about teaching process when need to make some screen in the teaching material content. In the choice to teach content Along with the original is:

(1) And direction of electronic information engineering of various process of class teaching learning progress, reasonable choice of teaching content.

(2) Real use sex in classroom teaching, and strengthen students in communication circuit design of the square, accentuating the modern digital communication technology, the effectiveness of the system on the letter and reliable technology

(3) Before the technology as the support, develop students view, for the subsequent course cheng good shop pad.

For this, I have capacity within the teaching, to teach effectively integrates a suitable sequence, which is suitable for the school of electronic information engineering specialty to write letter principle teaching material, teaching outline, to improve the teaching effect of this course has played a good use.

\section{Improvement of the Experimental Teaching}

In the course of experiments, communication principle, the traditional experiment in part through the communication principle experiment box to verify this teaching theory, and the lack of a comprehensive system experiment and design type of experiments. Comprehensive design experiment is to break the existing scheme, under the condition of some specific requirements and their own comprehensive new experiment schemes and steps, to complete the requirements of the experiments. Because of this composite has higher flexibility, requires students to master the basic knowledge and basic methods in strong under the premise of creative, therefore, in order to comprehensive design experiment as the carrier, is to cultivate students' comprehensive and creative thinking ability is one of the important way. Through the comprehensive design experiment can make students better grasp the experiment principle, operation methods, steps, a comprehensive 
understanding of the performance of the equipment and proper use of equipment, training students thinking and the ability to analyze and solve problems, improve the comprehensive thinking ability of students. By conducting the work, will be good for schools to cultivate the high quality, comprehensive and innovative talents social needed. To this end, we will introduce MATLAB experiment teaching. Requires students themselves using the MATLAB software powerful graphics functions convert theoretical formula to graphic expression, the simulation analysis. Students can use MATLAB software to comprehensive design experiment system and simulation, such as direct sequence spread spectrum technology design, OFDM receiver transmitter system, etc. These comprehensive design experiment system, and only through the use of communication principle experiment box cannot complete without hardware may carry on the simulation by MATLAB software, obtain good effect. Through MATLAB simulation, on the one hand, make originally boring static theory knowledge become "move" rise, greatly stimulated the students' interest in study. For other modem system of textbooks, students learn to use the simulation method to establish model parameters, the simulation analysis of the "mystery", quickly mastered the relevant principle, avoid the repeated before the theoretical interpretation of the students still don't understand the situation, greatly improve the classroom teaching quality and learning efficiency [5]. With class, on the other hand, guide the use of simulation teaching, students were drawn into the design of the communication system research environment, greatly enhanced the enthusiasm of autonomous learning. Students after class of build communication system, simulation are clarified and discussed more conducive to the classroom to absorb knowledge, at the same time easy is closely linked with engineering practice, conducive to the cultivation of innovation ability. Using MATLAB continuous updates to launch all kinds of library resources, and the library resources is closely related to the latest research and application, can easily complete many comprehensive system of new type communication system design and simulation, for does not meet the given teaching materials and teaching contents of students, especially at the present stage of our school recruit students of an excellent student, you can keep up with the development of professional disciplines, introduction of MATLAB simulation experiments for their reserve enough learning and development space.

\section{Conclusion}

Based on the principle of communication curriculum teaching concept, teaching methods, teaching content and the reform of experimental teaching, and in the actual teaching of the students in practical use, very good solution to the teaching content and the contradiction between the period of less. Students generally reflect the communication principle course no imagination so difficult to learn, it is very boring tedious tasteless theory knowledge, through the above reform of the course, make students easy to understand, greatly improve the efficiency of the quality of classroom teaching and learning, and stimulate the enthusiasm of students learning, gain good teaching effect.

\section{Acknowledgement}

In this paper, the research was sponsored by the professional comprehensive reform project of electronic information engineering of Foshan University.

\section{References}

[1] Zhigang Cao. Principle of Communication(the sixth edition)[M], National defence industry press, Beijing,2010.

[2] Rongfen Zhang. The exploration of innovative teaching and research of Modern communication principle[J].Course Education Research,2013,7(7):254-255.

[3] Faquan Yang. Communication systems modeling and simulation in MATLAB[M]. Tsinghua university press, 2015 
[4] Wenli Shen, Yanping Yu. Class and experiment teaching reform of principles of communication [J]. Experiment Science and Technology,2014,12(1):55-58.

[5] Jean Liu, Yiping Chang. The exploration and practice of inadequate teaching hours about the communication principle course[J]. Education Technology and Equipment in China,2014,14:77-79. 